\section{Colonoscope incarceration in an inguinal hernia: a complication of colonoscopy}

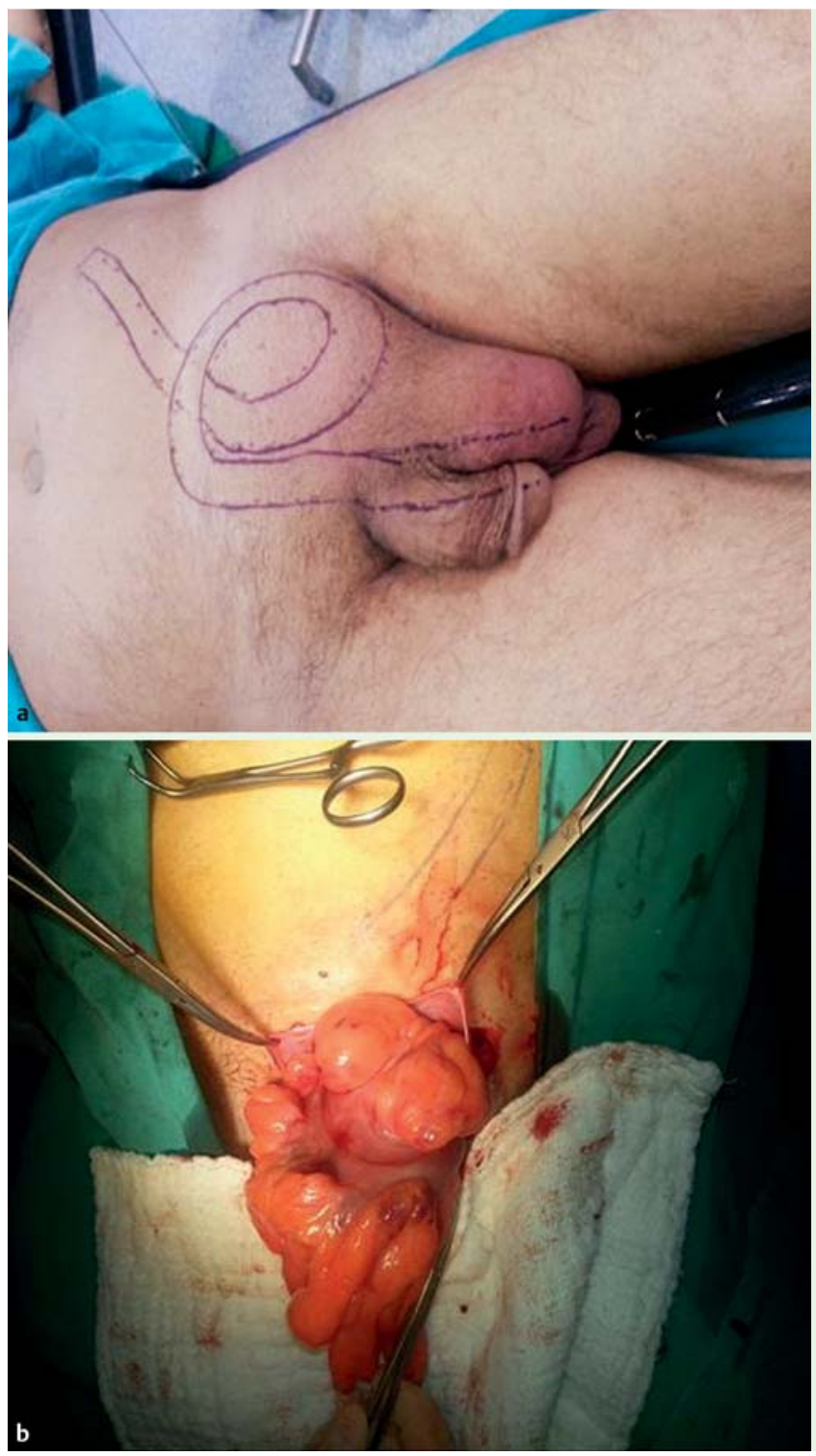

Fig. 1 Photographs showing: a incarceration of the colonoscope in the inguinal hernia sac; $\boldsymbol{b}$ the patient's left inguinal hernia during surgery.

One of the rare complications of colonoscopy is incarceration of the colonoscope in an inguinal hernia [1,2]. We present a case of incarceration of the colonoscope in a left-sided hernia, which required reduction of the hernia by surgical dissection of the hernial sac.

A 70-year-old man who presented with iron deficiency anemia underwent colonoscopy. The procedure was performed easily until the ascending colon was reached, at which point it became impos-
The patient was given $6 \mathrm{mg}$ midazolam and $100 \mathrm{mg}$ pethidine as analgesia, whilst an attempt was made to manually reduce the incarcerated colonoscope using external manual pressure. This attempt was unsuccessful. Under fluoroscopy, a loop of the colonoscope could be seen in the left inguinal hernia ( Fig.2) but, despite radiographic guidance, it was not possible to withdraw the colonoscope using gentle traction. Therefore, the patient underwent surgery, with a hernia repair operation being done and the colonoscope being withdrawn by traction. The patient was discharged 2 days later.

Commonly, it is a left-sided inguinal hernia, as our patient had, that is involved in this complication. Importantly, a careful history should be taken and physical examination of the inguinal region should be performed before a patient undergoes colonoscopy to avoid the risk of colonoscope incarceration in an inguinal hernia. If incarceration of the colonoscope in an inguinal hernia does occur, there are different methods to reduce the incarcerated colonoscope, including manual reduction, reduction under direct fluoroscopic guidance, and surgical reduction, as was required for our patient [3].

Finally, if a colonoscope cannot be advanced although the lumen is clearly seen, incarceration of the colonoscope in an inguinal hernia should be considered.

Endoscopy_UCTN_Code_CPL_1AJ_2AB

Competing interests: None

Adnan Tas ${ }^{1}$, Cem Oruç²,

Sehmus Olmez ${ }^{3}$, Mustafa Şahan ${ }^{4}$, Mustafa Uğur ${ }^{2}$, Sedat Hakimoğlư ${ }^{5}$, Mehmet Demir ${ }^{1}$

${ }^{1}$ Department of Gastroenterology, Mustafa Kemal University Medical Faculty, Hatay, Turkey

2 Department of General Surgery, Mustafa Kemal University Medical Faculty, Hatay, Turkey

${ }^{3}$ Department of Gastroenterology, Yuzuncu Yil University Medical Faculty, Van, Turkey

${ }^{4}$ Department of Emergency, Mustafa Kemal University Medical Faculty, Hatay, Turkey

${ }^{5}$ Department of Anesthesiology and Reanimation, Mustafa Kemal University Medical Faculty, Hatay, Turkey 

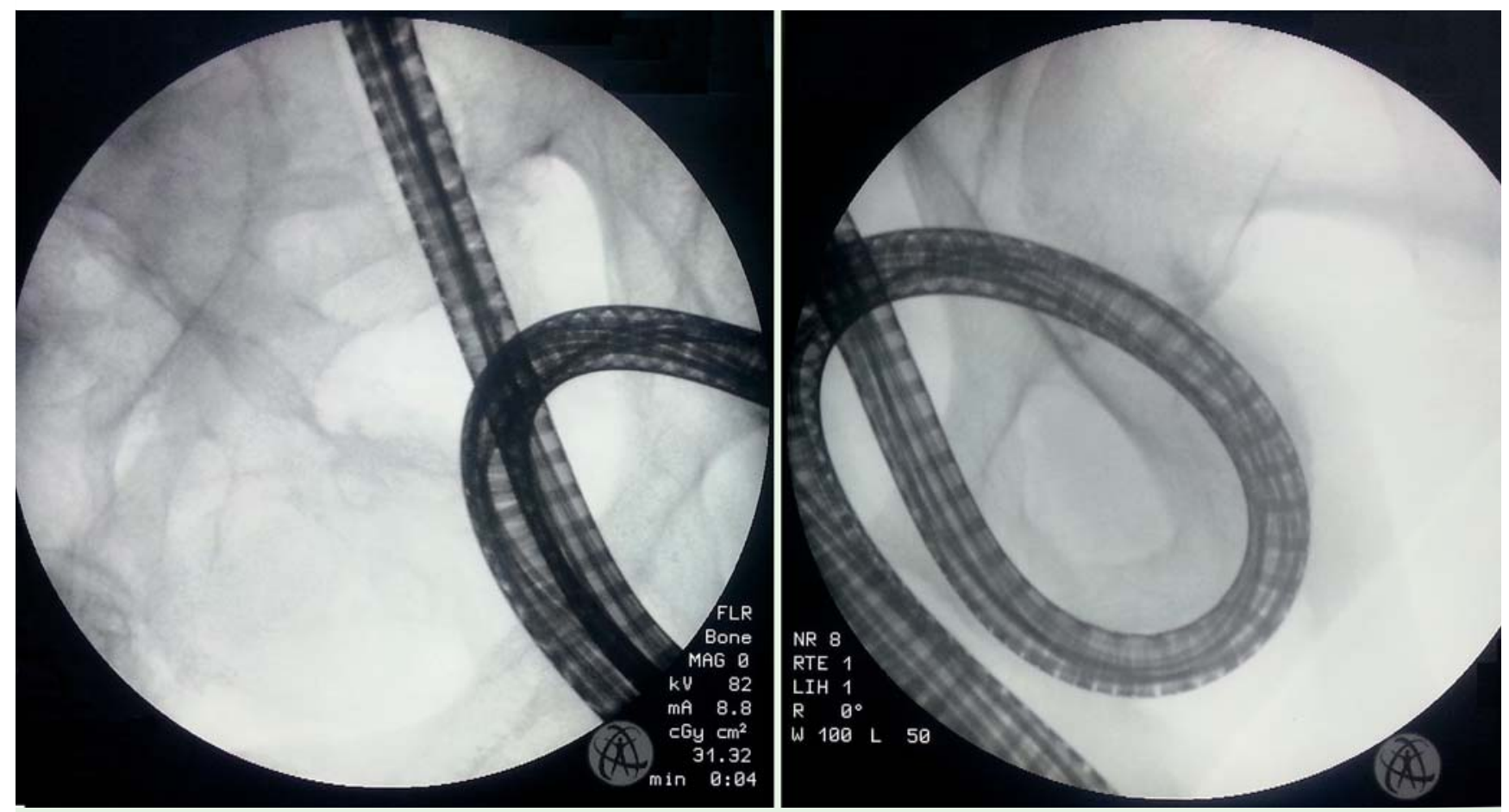

Fig. 2 Fluoroscopic images showing a loop of the colonoscope within the left inguinal hernia.

\section{References}

1 Day LW, Kwon A, Inadomi JM et al. Adverse events in older patients undergoing colonoscopy: a systematic review and meta-analysis. Gastrointest Endosc 2011; 74: 885-896

2 Tan VP, Lee YT, Poon JT. Incarceration of a colonoscope in an inguinal hernia: Case report and literature review. World J Gastrointest Endosc 2013; 5: 304-307

3 Fan CS, Soon MS. Colonoscope incarceration in an inguinal hernia. Endoscopy 2007; 39 (Suppl. 01): E185

\section{Bibliography}

Dol http://dx.doi.org/

10.1055/s-0034-1391338

Endoscopy 2015; 47: E125-E126

(c) Georg Thieme Verlag KG

Stuttgart - New York

ISSN 0013-726X

\section{Corresponding author \\ Adnan Tas, MD \\ Çekmece Caddesi \\ Çekmece Mahallesi \\ Bina no:2 Defne/Hatay \\ Turkey \\ dradnantas@gmail.com}

